\title{
Effect of anthocyanins on selected biochemical parameters in rats exposed to cadmium ${ }^{*}$
}

\author{
Edward Kowalczyk ${ }^{1 凶}$, Anna Kopff ${ }^{2}$, Paweł Fijałkowski ${ }^{1}$, Maria Kopff ${ }^{2}$, \\ Jan Niedworok ${ }^{1}$, Jan Błaszczyk ${ }^{1}$, Józef Kędziora ${ }^{1}$ and Piotr Tyślerowicz ${ }^{1}$ \\ ${ }^{1}$ Department of Human Physiology and Biophysics, ${ }^{2}$ Department of Chemistry and Clinical \\ Biochemistry, Medical University, Eódż, Poland
}

Received: 10 March, 2003; revised: 29 April, 2003; accepted: 21 May, 2003

Key words: cadmium, anthocyanins, biochemical parameters

\begin{abstract}
Cadmium is a dangerous occupational and environmental toxin. It accumulates in the human organism mainly in liver and kidneys. Cadmium half-life is about 10 years, so the symptoms of cadmium intoxication may occur several years after the exposure. Until now in treating intoxication with this metal chelating compounds have been used, burdened with numerous undesirable symptoms. In our investigations anthocyanins from Aronia melanocarpa were used to reduce the harmful results caused by cadmium. Administering anthocyanins with cadmium chloride resulted in a statistically significant decrease of aspartate aminotransferase (AST) and alanine aminotransferase (ALT) activity, concentration of bilirubin and urea in blood serum and decreased cadmium cumulation in liver and kidneys in relation to animals receiving cadmium chloride only.
\end{abstract}

Cadmium is one of the most dangerous occupational and environmental toxins. It is found in drinking water, atmospheric air and even in food. Products of vegetable origin are the main carrier of cadmium compounds in food (Kłos, 2001). Having been absorbed from the alimentary tract, cadmium forms durable combinations with the protein thionein, form- ing metallothioneins which play an important role in further metabolism of this metal. Kidneys (mainly renal cortex) and liver are considered to be the most susceptible organs in the case of exposure to cadmium (Ryan et al., 2000; Yamano et al., 1999; Yiin et al., 1999). The damaging effect of cadmium on the liver is manifested by an increase of aspartate

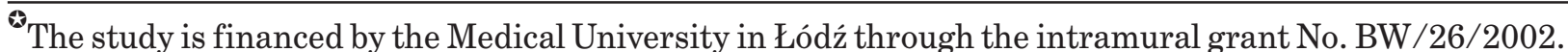

${ }^{\otimes}$ Address for correspondence: Edward Kowalczyk, Department of Human Physiology and Biophysics, Medical University, Plac J. Hallera 1, 90-647 Łódź, Poland; fax: (48 42) 636 8683;

e-mail: farmak@achilles.wam.lodz.pl (or e-mail: akopff@wp.pl)
}

Abbreviations: ALT, alanine aminotransferase; AST, aspartate aminotransferase; Hgb, haemoglobin; PTWI, provisional tolerable weekly intake; RBC, red blood cells. 
aminotransferase (AST) and of the most specific marker of liver cell damage - alanine aminotransferase (ALT). Sauer et al. (1997) and Blasco \& Puppo (1999) also observed an increase of the activity of these enzymes as a result of cadmium activity. Cadmium hepatotoxicity is probably effected in two ways: on the one hand by the occurrence of inflammatory state, on the other hand - by direct toxic action of cadmium on liver cells. So far in treating cadmium intoxications chelating compounds have been used, e.g. calcium disodium versenate, dimercaprol and mesomercaptosuccinic acid (Shaikh et al., 1999; Piotrowski et al., 1995). In the recent years in scientific investigations attention has been drawn to the "health-promoting" activity of vegetable pigments, among them anthocyanins (Oszmiański, 2001; Hertog et al., 1993). Due to the commonness of occurrence, anthocyanins are abundant components of human diet (fresh fruit, juices, wine). As yet, a toxic effect of anthocyanins on humans and animals has not been shown (Oszmiański, 2001). Anthocyanins demonstrate anti-inflammatory (Subarnas \& Wagner, 2000) and antioxidative activity (Oszmiański, 2001; Subarnas \& Wagner, 2000; Wolniak, 2002; Tsuda et al., 1999; Wang, 2000), and they are able to chelate metal ions (Wawer, 2001). Anthocyanins increase the resistance of hepatocytes to oxidation, activate liver enzymes (aspartate aminotransferase, alanine aminotransferase and lactate dehydrogenase) and lower the reduced glutathione concentration in the liver.

The aim of the study was to evaluate the effect of anthocyanins from Aronia melanocarpa on the selected biochemical parameters in rats exposed to cadmium.

\section{MATERIAL AND METHODS}

Wistar rats (male) with mean mass $210 \pm$ $15 \mathrm{~g}$ were kept in animal quarters with stable temperature and humidity. The animals were divided into four groups, 10 in each of them. They received daily for 30 days with a stomach tube: group I (control) $-0.5 \mathrm{ml}$ of drinking water; group II - aqueous solution of anthocyanins from Aronia melanocarpa (described below) $10 \mathrm{mg} / \mathrm{kg}$ of body mass; group III - in the form of aqueous solution, cadmium chloride $\left(\mathrm{CdCl}_{2} \times 2.5 \mathrm{H}_{2} \mathrm{O}\right) 4.0 \mu \mathrm{g} / \mathrm{kg}$ of body mass; group IV - cadmium chloride in the dose as in group III and $4 \mathrm{~h}$ after administering cadmium chloride, anthocyanins as in group II. The aqueous solution of anthocyanins from Aronia melanocarpa (Agropharm, Poland) composed of: 3-O-cyanidin galactoside (64.5\%), 3-O-cyanidin arabinoside (28.9\%), 3-O-cyanidin xyloside $(4.2 \%)$ and 3-O-cyanidin glucoside (2.4\%). In the course of the experiment the animals were fed with standard feed stuff for small laboratory animals (Murigran) and they had free access to drinking water. After 30 days the animals were terminated in general narcosis and blood, liver and kidneys were collected for the determination of:

1. in blood, erythrocyte count, haemoglobin concentration, haematocrite value using SELAB system;

2. in blood serum, urea, creatinine, bilirubin levels and AST and ALT activity using a Kone-Pro biochemical analyzer and Bio-Merieux reagents;

3. in liver and kidneys, content of cadmium with atomic emission spectrometry with plasmic excitation in a ICP PU 7000 apparatus (Unicam, Cambridge). Organs were mineralized in teflon containers in a closed system in a microwave oven MLS 1200 Mega (Milestone, Bergamo). Analytical curves were made from Baker Standards (Philipsburg, U.S.A.).

The results were analysed statistically with U Mann-Whitney non-parametric test using the Statistica program.

The investigations were carried out with the approval of the Local Ethics Committee No. $\mathrm{七} / \mathrm{BD} / 121$. 


\section{RESULTS AND DISCUSSION}

The effects of anthocyanins from Aronia melanocarpa on selected liver and renal function biochemical tests (ALT and AST activities, bilirubin, urea and creatinine serum concentration) and the content of cadmium in animals receiving cadmium chloride were presented in Table 1.
The mechanism of the harmful activity of cadmium is not fully explained. It seems that the toxicity of this metal on the one hand lies in a direct action of free cadmium ions not bound with metallothionein, while on the other hand, in forming (under the influence of cadmium) reactive radicals being able to change functions and structure of many systems and organs (Kowalczyk et al., 2002;

Table 1. Effect of anthocyanins on selected biochemical parameters and content of cadmium in rats receiving cadmium chloride.

Conditions of experiments are described in Material and Methods.

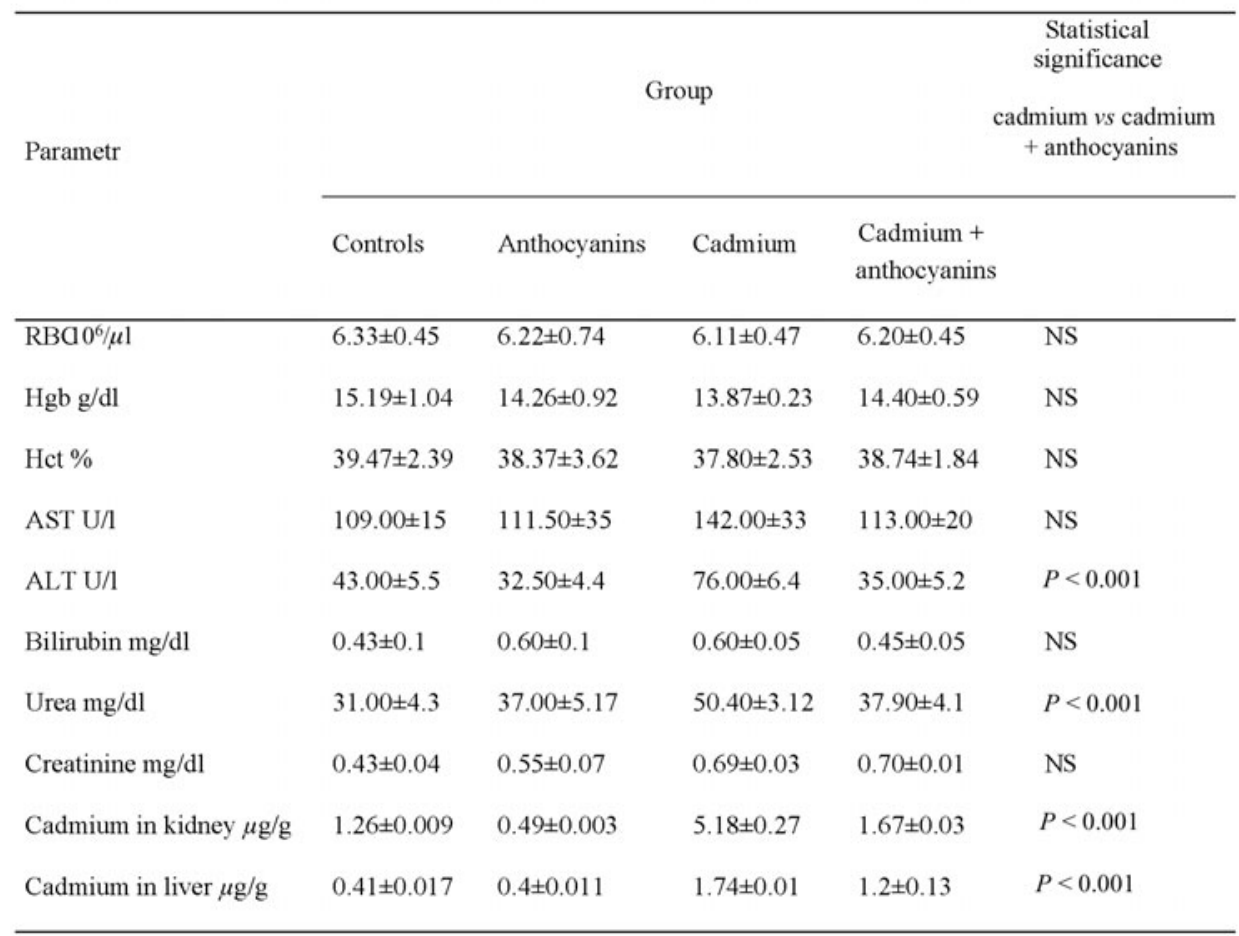

Administering cadmium chloride to rats resulted in a statistically significant decrease of haemoglobin concentration in blood in relation to the control group. Adding anthocyanins to cadmium chloride did not normalize the haemoglobin concentration, while it significantly decreased AST and ALT activity, concentration of bilirubin and urea in blood serum (the above parameters were increased after administering cadmium chloride alone). The anthocyanins also statistically significantly decreased the accumulation of cadmium in liver and kidneys.
Stohs et al., 2001). As a result of exposure to cadmium there develops, among others, hypochromic anaemia. Several mechanisms leading to anaemia have been suggested. Cadmium may compete with iron, leading to the occurrence of anaemia due to iron deficiency, whereas on the other hand renal failure, developing under the influence of cadmium, results in erythropoietin deficiency which may cause normochromic and normocytic anaemia without a proportional increase of reticulocytes (Hiratsuka et al., 1996; Mackova et al., 1996). Chun et al. (2000) are of the opinion that cad- 
mium ions significantly affect regulatory genes for erythropoietin, which may be the cause of inhibiting its expression. In our investigations a slight decrease of haematologic value was observed in the group of animals receiving cadmium, which may be connected with the short time of exposure (30 days) or with too small a dose of cadmium used in the experiment. According to $\mathrm{FAO} / \mathrm{WHO}$, provisional tolerable weekly intake (PTWI) for cadmium in man is $0.0067 \mathrm{mg} /$ week per $\mathrm{kg}$ of body mass. Due to the quicker metabolism in rats, the dose of cadmium was increased four times. The application of anthocyanins resulted in a slight improvement of haematologic values.

It has been known for a long time that cadmium mainly accumulates in liver and kidneys because these organs contain most of metallothionein binding toxic metals (Choudhury et al., 2001; Hollis et al., 2001; Liu et al., 1998; Yiin et al., 1999). Of considerable interest is the decrease of cadmium accumulation in liver and kidneys in the animals receiving anthocyanins in addition to cadmium, observed in our investigation. It may testify to the possibility of anthocyanins chelating cadmium ions which in consequence may decrease the damages caused by this metal. Cadmium accumulation in liver and kidneys results in functional changes and then in interstitial fibrosis of these organs.

The anthocyanins used in our investigations demonstrate protective action against the damages of hepatocytes by cadmium, for they normalize the acitivities of liver enzymes (AST, ALT). A protective effect of anthocyanins on liver cells has also been observed by Tsuda et al. (1999).

Another sensitive indicator of liver cell damage is the concentration of total bilirubin in plasma. Novelli et al. (1998) reported a significant increase of total bilirubin concentration in rats exposed to cadmium. Sarkar et al. (1998) found that the increase of total bilirubin concentration in plasma after intoxication with cadmium correlates with the oxidative damage of other organs resulting from oxidative stress.

In our investigations we observed a considerable increase of total bilirubin concentration in plasma of rats which were given cadmium chloride. Additional administration of anthocyanins resulted in a statistically significant lowering of the increase of total bilirubin concentration in plasma caused by cadmium treatment. The observed beneficial changes may result from the antioxidative activity of anthocyanins which was the subject of numerous scientific reports (Oszmiański, 2001; Subarnas \& Wagner, 2000; Wolniak, 2002; Tsuda et al., 1999; Wang, 2000).

As a result of cadmium activity one notices also renal tubule damage and then glomerular filtration impairment (Shibutani et al., 2001). This may account for the increase of urea and creatinine concentration in the animals receiving cadmium chloride. The damaging effect of cadmium on kidneys has also been described by other authors (Jarup et al., 2000; Jarup, 2002). Simultaneous administration of anthocyanins with cadmiumn chloride significantly decreases the concentration of urea in blood with no significant decrease of the creatinine value. The mechanism of the beneficial effect of anthocyanins on kidneys is undoubtedly heterogeneous. Anthocyanins decrease the inflammatory process (they inhibit cyclooxygenase- 1 and -2) (Subarnas \& Wagner, 2000), decontract blood vessels and improve microcirculation (Bertuglia, 1995).

In our investigations a decrease of concentration of oxidative stress biomarkers was observed in animals receiving cadmium chloride and anthocyanins in relation to those receiving only cadmium chloride (in preparation). Although the mechanism of the action of anthocyanins in human organism is still unexplained, their multidirectional activities account for the application of anthocyanins in many diseases. 


\section{CONCLUSIONS}

1. Administering anthocyanins from Aronia melanocarpa with cadmium chloride decreases:

a) the activity of AST, ALT enzymes, bilirubin and urea concentration in blood serum;

b) cadmium concentration in liver and kidneys.

2. The use of anthocyanins in prophylaxis or therapy of people exposed to increased cadmium concentration requires carrying out investigations with the use of more numerous studied groups and evaluating the dependence of the effect upon the dose of anthocyanins.

\section{R E F E R E N C E S}

Bertuglia S. (1995) Efect of Vaccinium myrtillus anthocyanosides on ischemia reperfusion injury in hamster cheek pouch microcirculation. Pharmacol Res., 31: 183-7.

Blasco J, Puppo J. (1999) Effect of heavy metals $(\mathrm{Cu}, \mathrm{Cd}$ and $\mathrm{Pb})$ on aspartate and alanine aminotransferase in Ruditapes philippinarum (Mollusca: Bivalvia). Comp Biochem Physiol Pharmacol Toxicol Endocrinol.; 122: 253-63.

Choudhury H, Harvey T, Thayer WC, Lockwood TF, Stiteler WM, Goodrum PE, Hassett JM, Diamond GL. (2001) Urinary cadmium elimination as a biomarker of exposure for evaluating a cadmium dietary exposure biokinetics model. J Toxicol Environ Health.; 63: $321-250$.

Chun YS, Choi E, Kim GT, Choi H, Kim CH, Lee MJ, Kimm S, Park JW. (2000) Cadmium blocks hypoxia-inducible factor (HIF)-1-mediated response to hypoxia by stimulating the proteasome-dependent degradation of HIF-1alpha. Eur J Biochem.; 267: 4198-204.

Hertog MG, Hollman PC, Katan MB, Kromhout D. (1993) Intake of potentially anticarcinogenic flavonoids and their determinants in adults in The Netherlands. Nutr Cancer.; 20: 21-9.
Hiratsuka H, Katsuta O, Toyota N, Tsuchitani M, Umemura T, Marumo F. (1996) Chronic cadmium exposure-induced renal anemia in ovariectomized rats. Toxicol Appl Pharmacol.; 137: $228-36$.

Hollis L, Hogstrand C, Wood CM. (2001) Tissuespecific cadmium accumulation, metallothionein induction, and tissue zinc and copper levels during chronic sublethal cadmium exposure in juvenile rainbow trout. Arch Environ Contam Toxicol.; 41: 468-74.

Jarup L. (2002) Cadmium overload and toxicity. Nephrol Dial Transplant.; 17 (Suppl 2): 35-9.

Jarup L, Hellstrom L, Alfven T, Carlsson MD, Grubb A, Persson B, Pettersson C, Spang G, Schultz A, Elinder CG. (2000) Low level exposure to cadmium and early kidney damage: the OSCAR study. Occup Environ Med.; 57: 668-72.

Kłos A. (2001) Lead, cadmium and mercury content in meals planned for consumption in selected kindergartens in Warsaw. IV International Scientific-Technical Conference, Warsaw 4-5X.

Kowalczyk E, Jankowski A, Niedworok J, Śmigielski J, Tyślerowicz P. (2002) Effect of long-term cadmium intoxication on selected biochemical parameters in experimental animals. Pol J Environ Stud.; 11: 599-601.

Liu J, Habeebu SS, Liu Y, Klaassen CD. (1998) Acute CdMT injection is not a good model to study chronic $\mathrm{Cd}$ nephropathy: comparison of chronic $\mathrm{CdCl}_{2}$ and $\mathrm{CdMT}$ exposure with acute CdMT injection in rats. Toxicol Appl Pharmacol.; 153: 48-58.

Mackova NO, Lenikova S, Fedorocko P, Brezani P. (1996) Effects of cadmium on haemopoiesis in irradiated and non-irradiated mice: 2 . Relationship to the number of circulating blood cells and haemopoiesis. Physiol Res.; 45: 101-6.

Novelli EL, Vieira EP, Rodrigues NL, Ribas BO. (1998) Risk assessment of cadmium toxicity on hepatic and renal tissues of rats. Environ Res.; 79: 102-5.

Oszmiański J. (2001) Aronia ( Aronia melanocarpa Elliot) fruits and skullcap 
(Scutellaria baicalensis Georgi) roots are very high in biologically active flavonoids. Farm Pol.; 15: 726-30.

Piotrowski JK, Moniuszko-Jakoniuk J. (1995) Zarys toksykologii kadmu. Medycyna Pracy.; 5 (Suplp. 5): 32-6.

Ryan PB, Huet N, Maclntosh DL. (2000) Longitudinal investigation of exposure to arsenic, cadmium and lead in drinking water. Environ Health Perspect.; 108: 731-5.

Sarkar S, Yadav P, Bhatnagar D. (1998) Lipid peroxidative damage on cadmium exposure and alterations in antioxidant system in rat erythrocytes: a study with relation to time. Biometals.; 11: 153-7.

Sauer JM, Waalkes MP, Hooser SB, Kuester RK, McQueen CA, Sipes IG. (1997) Suppression of Kupffer cell function prevents cadmium induced hepatocellular necrosis in the male Sprague-Dawley rat. Toxicology.; 121: 155-64.

Shaikh ZA, Jordan SA, Tang WF. (1999) Protection against chronic cadmium toxicity by caloric restriction. Toxicology.; 133: 93-103.

Shibutani M, Mitsumori K, Satoh S, Hiratsuka H, Satoh M, Sumiyoshi M, Nishijima M, Katsuki Y, Suzuki J, Nakagawa J, Akagi T, Imazawa T, Ando M. (2001) Relationship between toxicity and cadmium accumulation in rats given low amounts of cadmium chloride or cadmium-polluted rice for 22 months. $J$ Toxicol Sci.; 26: 337-58.
Stohs SJ, Bagchi D, Hassoun E, Bagchi M. (2001) Oxidative mechanisms in the toxicity of chromium and cadmium ions. J Environ Pathol Toxicol Oncol.; 20: 77-82.

Subarnas A, Wagner H. (2000) Analgesic and anti-inflammatory activity of the proanthocyanidin shellegueain A from Polypodium feei METT. Phytomedicine.; 7: 401-5.

Tsuda T, Horio F, Kitoh J, Osawa T. (1999) Protective effects of dietary cyanidin 3-O-beta-D-glucoside on liver ischemia-reperfusion injury in rats. Arch Biochem Biophys.; 368: 361-6.

Wang HK. (2000) The therapeutic potential of flavonoids. Expert Opin Investig Drugs.; 9: 2103-19.

Wawer I. (2001) Anthocyanidins, structure and antioxidant properties. Farm Pol.; 15: 728-31.

Wolniak M. (2002) Mechanisms of antioxidative action of anthocyanins. Farm Pol.; 20: 931-4.

Yamano T, Kosanke SD, Rikans LE. (1999) Attenuation of cadmium-induced liver injury in senescent male Fischer 344 rats: role of metallothionein and glutathione. Toxicol Appl Pharmacol.; 161: 225-30.

Yiin SJ, Chern CL, Sheu JY, Tseng WC, Lin TH. (1999) Cadmium induced renal lipid peroxidation in rats and protection by selenium. J Toxicol Environ Health.; 57: 403-13. 